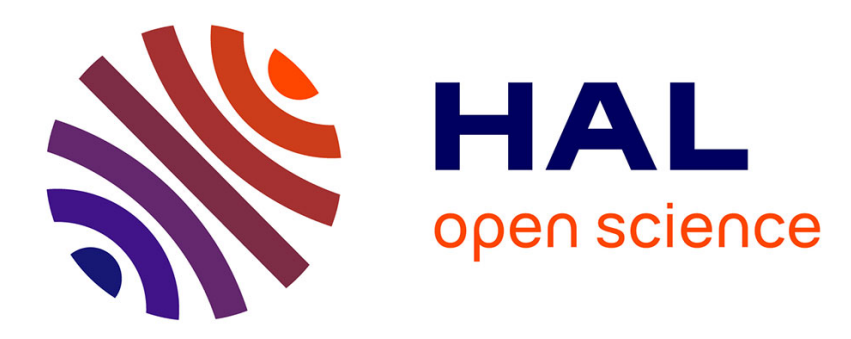

\title{
The Bent Pyramid and the Major Lunar Standstill
} Amelia Carolina Sparavigna

\section{To cite this version:}

Amelia Carolina Sparavigna. The Bent Pyramid and the Major Lunar Standstill. 2018. hal-01736707

\author{
HAL Id: hal-01736707 \\ https://hal.science/hal-01736707 \\ Preprint submitted on 18 Mar 2018
}

HAL is a multi-disciplinary open access archive for the deposit and dissemination of scientific research documents, whether they are published or not. The documents may come from teaching and research institutions in France or abroad, or from public or private research centers.
L'archive ouverte pluridisciplinaire HAL, est destinée au dépôt et à la diffusion de documents scientifiques de niveau recherche, publiés ou non, émanant des établissements d'enseignement et de recherche français ou étrangers, des laboratoires publics ou privés. 


\title{
The Bent Pyramid and the Major Lunar Standstill
}

\author{
Amelia Carolina Sparavigna \\ Department of Applied Science and Technology \\ Politecnico di Torino
}

Here it is given a discussion about the orientation of the causeway which is linking the Bent Pyramid to its Valley Temple. Using mooncalc.org software we can see that the causeway has an orientation that could have been determined according to the northernmost direction of the moonrise, which happens on a major lunar standstill. By means of the simulation, we can also see that, at the latitude of Dahshur, on such a major lunar standstill in the northernmost direction, the moon reaches an altitude of 89 degrees, having therefore a passage close to the zenith of the sky. Using software Stellarium, we can see that an orientation of the causeway to the rising of Capella is also possible. However, I consider more plausible an orientation to the northernmost direction of the moonrise.

Submitted HAL, March 18, 2018.

The Bent Pyramid is an ancient spectacular pyramid that we can find at the royal necropolis of Dahshur. It was built under Sneferu, Pharaoh of the Old Kingdom, (c. 2600 BC). This was the second pyramid built by Sneferu after that of Meidum. The profile of the bent pyramid is peculiar: the lower part of the pyramid rises from the desert at an inclination of 54 degrees, but the upper part has an inclination of 43 degrees. For this reason, the pyramid gained its name of 'bent pyramid'. The origin of the change of inclination is commonly attributed to the fact that, due to the steepness of the original inclination, the building had shown signs of instability during its construction, forcing the builders to change their project to prevent a collapse of the structure.

As observed by Wikipedia, https://en.wikipedia.org/wiki/Bent_Pyramid, this pyramid is "also unique amongst the approximately ninety pyramids to be found in Egypt, in that its original polished limestone outer casing remains largely intact". We can also read in Wikipedia that the "ancient formal name of the Bent Pyramid is generally translated as (The)-SouthernShining-Pyramid, or Sneferu-(is)-Shining-in-the-South". In the Figure 1, a simulation of the landscape of the Bent Pyramid is given thanks to Google Earth. 


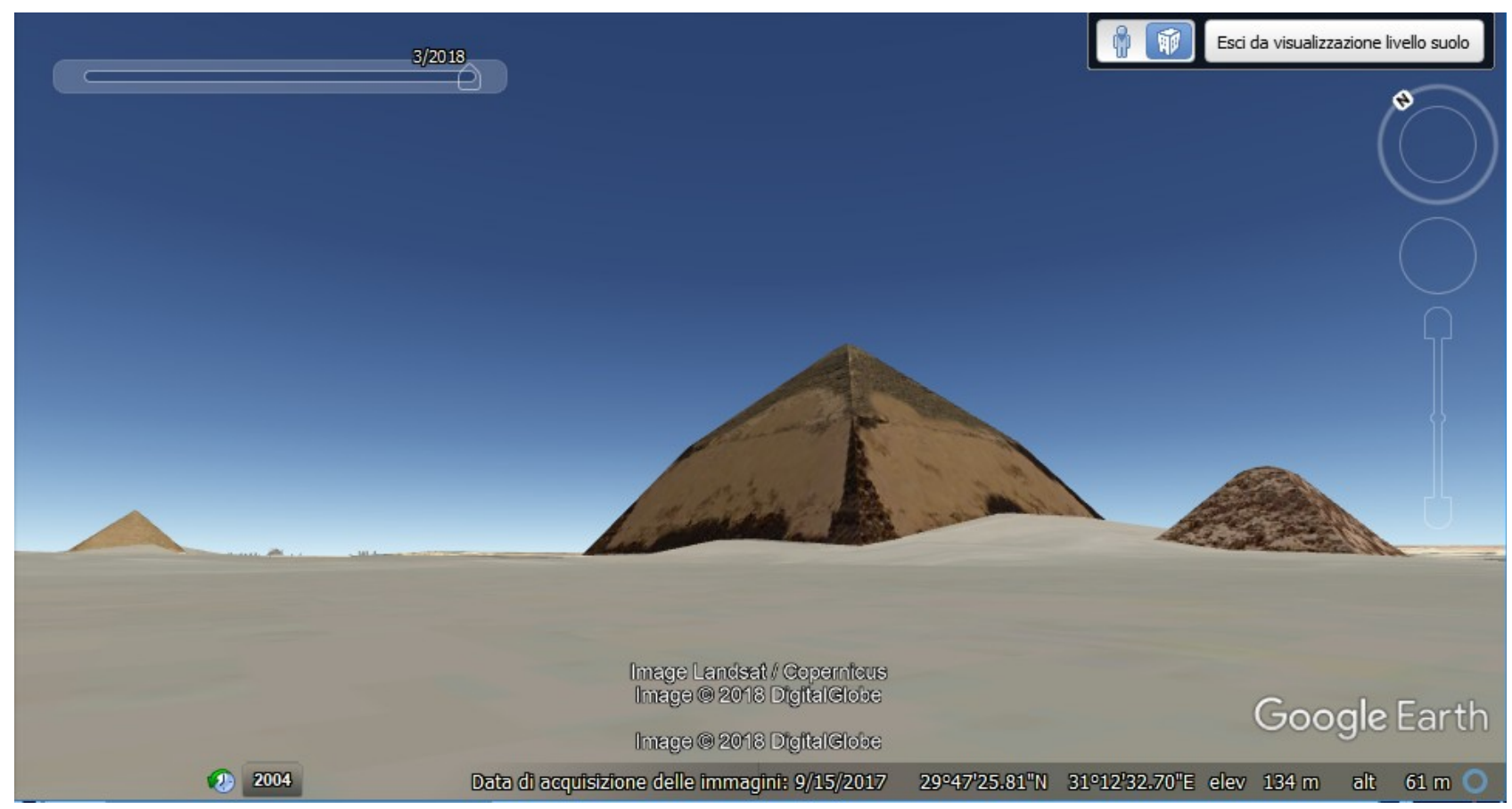

Figure 1: The Bent Pyramid and its satellite pyramid simulated by Google Earth. On the left, we can see the Red Pyramid. Google Earth is fundamental to understand the local landscape.

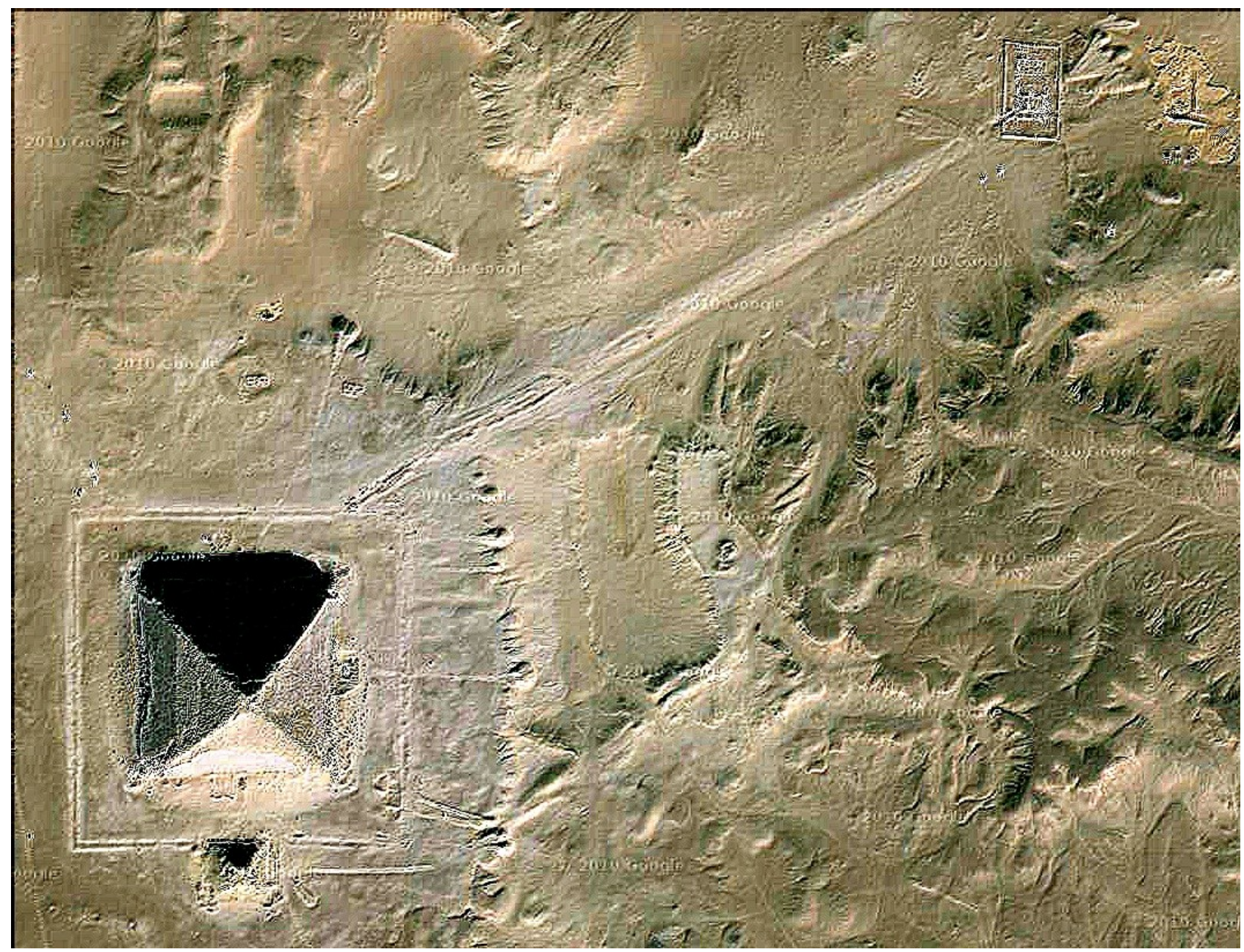

Figure 2: The Bent Pyramid and the causeway linking it to the Valley Temple, in a Google Earth image, processed to enhance the details. 
Located 55 meters south of the pyramid we can find a satellite pyramid, built to house the Pharaoh's Ka [1]. In [2], we can find information about the other structures of the pyramid complex. On the east side of the pyramid a small temple existed for the offering. A causeway is running from the north east of the courtyard surrounding the main pyramid, linking it to the valley temple (Figure 2). The causeway was paved with limestone blocks. As observed in [2], the valley temple was probably the first of its kind, because no valley temple has been found close to the pyramid of Sneferu at Meidum, "but from this point on the valley temple was a standard element of the pyramid complex".

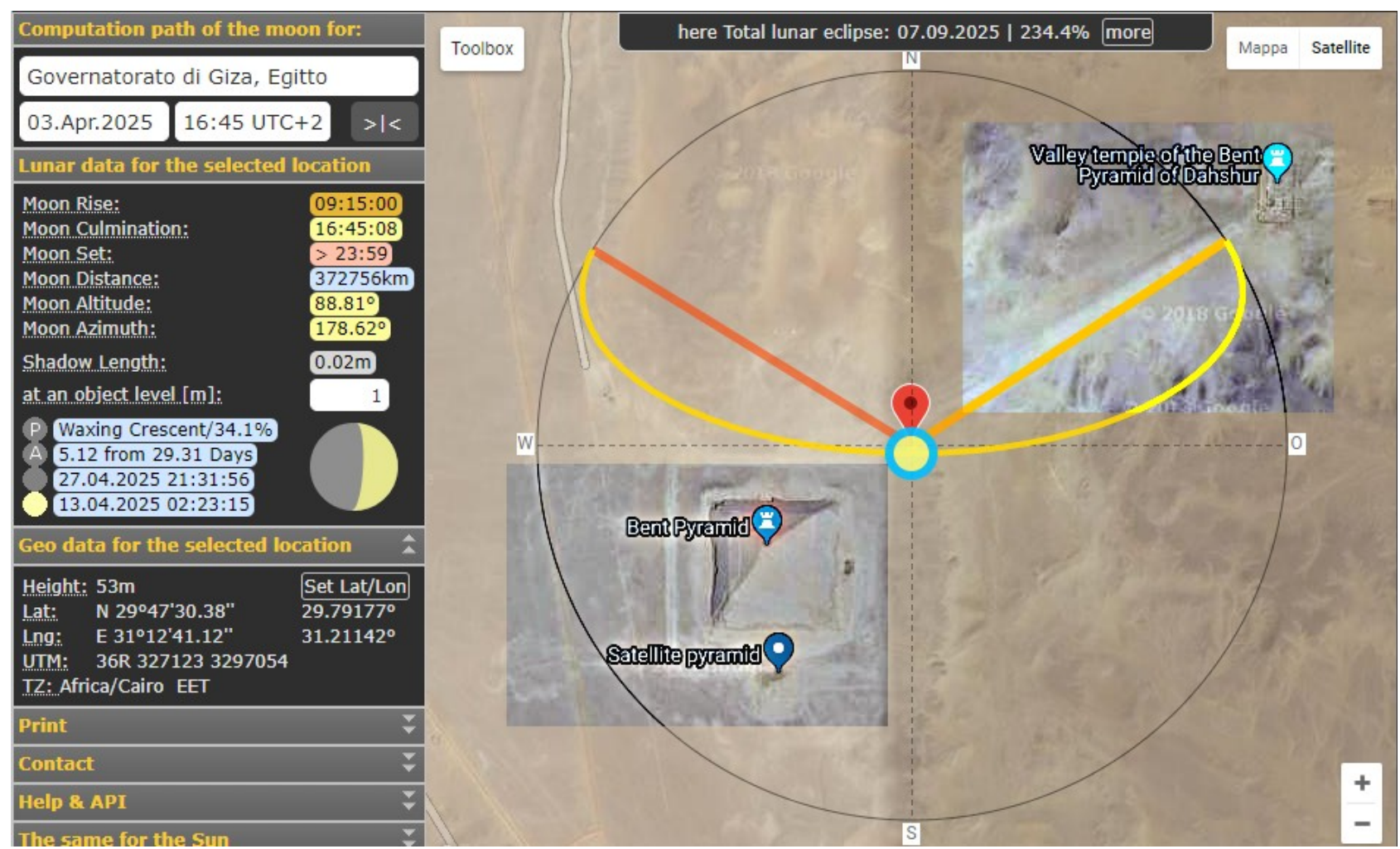

Figure 3: Simulation by means of Mooncalc.org of a major lunar standstill. We can see that the causeway is oriented along the direction of the northernmost rising of the moon. The yellow straight line represents the moonrise direction and the red line that of the moonset. The yellow curved line gives the apparent motion of the moon in the sky. As we can see, on a major lunar standstill in the northernmost direction, the moon can reach an altitude in the sky of 89 degrees. The moon therefore is passing close to the zenith of a local observer.

Let us consider the orientation of the causeway. However, before discussing the result given in the Figure 3, some words are necessary about the apparent motion of the moon. Of all the objects of the sky, the sun is the fundamental one; it has a clear and simple apparent motion, characterized by solstices and equinoxes, and by the zenith passages in 
the tropical zone [3]. From the winter solstice to the summer solstice, the sun increases its height in the sky and the angle between its rising and setting azimuths increases. It has an exactly opposite behavior from the summer solstice to the winter solstice.

The moon is obviously the other body attracting our attention: on the basis of its phases many aspects of natural calendars had been devised. However, the motion in the sky of our satellite was, for the ancients, more complex to analyze. The moon does not behave like the sun, being more intricate and "moody" [4]. On each month, the moon is like the sun on a year. For 14 days, the moon behaves like the sun during the time period from the summer solstice to the winter solstice, decreasing its altitude in the sky and having rising and setting azimuths moving southwards. For the other 14 days, the moon behaves like the sun from the winter solstice to the summer solstice; the moon increases its altitude in the sky and the rising and setting azimuths move northwards. A further complexity is due to the fact that, while the solar cycle is completed in 365 days, that of the moon lasts 18.6 years (the Metonic cycle). During this cycle the moon has a major standstill; on it, the moon reaches its maximum declination North, so that the moonrise azimuth is the northernmost possible one. In the same month, two weeks later, it has its rising at the southernmost possible azimuth, being closer to the South and lower on horizon.

During the Metonic cycle, a major standstill corresponds to the maximum declination of the Moon varying from roughly $28.5^{\circ}$ to $-28.5^{\circ}$, with a total movement of $57^{\circ}$ (as explained by Wikipedia in the item on lunar standstills, "enough to take its culmination from high in the sky to low on the horizon in just two weeks"). After 9.6 years the moon has a minor lunar standstill; the moon will change its declination during the nodal period from $+18.5^{\circ}$ to $-18.5^{\circ}$, which is a total movement of $37^{\circ}$, and then the angle spanned by the azimuth of moonrise and moonset is reduced to its minimum value.

Wikipedia (https://en.wikipedia.org/wiki/Lunar_standstill) tells us that we had a minor standstill in October 2015, and that we will have a major standstill in April 2025. So, let us consider the causeway linking the Bent Pyramid and the Valley Temple. The causeway had an azimuth of 57 degrees (from North). At Dahshur, the direction of the sunrise on summer solstice has an azimuth of 62 degrees, and therefore a solar orientation is not possible. We can suppose an orientation to the northernmost moonrise. To test this possibility we can use MoonCalc.org software. The result is given in the Figure 3. As we can see, the causeway is linking pyramid and temple in the direction of the northernmost moonrise which occurs on a major lunar standstill. Of course, it is possible that a small change of 
about half a degree, due to the slow change of the tilt of the Earth Axis [5], affects the result given in the Figure 3, but this is not influencing the result shown by the simulation.

As we can see from the Figure 3, when the moon is at a major lunar standstill, at the latitude of Dahshur, the moon is reaching 89 degrees in altitude. Therefore, it is passing close to the zenith of a local observer.

The orientation of the Bent Pyramid and its Valley Temple seems evidently linked to the moon. Here, let me report what Wikipedia is telling about the pyramids (https://en.wikipedia.org/wiki/Egyptian_pyramids): "The shape of Egyptian pyramids is thought to represent the primordial mound from which the Egyptians believed the earth was created. The shape of a pyramid is thought to be representative of the descending rays of the sun, and most pyramids were faced with polished, highly reflective white limestone, in order to give them a brilliant appearance when viewed from a distance. Pyramids were often also named in ways that referred to solar luminescence". Wikipedia continues mentioning the Bent Pyramid with its name of "Southern Shining Pyramid".

In the framework of this symbolic vision of the pyramids, it is plausible that the alignment of the causeway along the northernmost direction of the moonrise was deliberately decided to represent the apparent motion of the moon in the local horizon.

I consider also necessary to report what David Furlong is telling about the astronomical orientations of the Egyptian Temples [6]. "There is no accepted textual evidence that the Ancient Egyptians were able to predict eclipses and by inference then the Metonic cycle, although there is no practical reason why the lunar movements could not have been part of Egyptian temple orientation. Certainly the Moon took less precedence than the Sun in Egyptian mythology, nevertheless it was still regarded as an important body and there were a number of gods such as Thoth, Khonsu and lah that were associated with it". Actually, Furlong is mentioning two temples having a lunar alignment, the Seti I Temple at Qurna and the Ptah Temple at Karnak. Let me also mention the Great Enclosure of Musawwarat es Sufra, in the heartland of the Kingdom of Kush. In [7], I used the Photographer's Ephemeris, to see that the central part of the enclosure is aligned perfectly along the southern direction of the moonrise on a major lunar standstill, whereas the norther part of the enclosure has an orientation along the sunrise on the winter solstice.

Let us conclude this discussion, using the software Stellarium to simulate the sky seen by the pyramid, around $2600 \mathrm{BC}$. We can see that only Capella is rising in the direction of the causeway (see the Figure 4). 


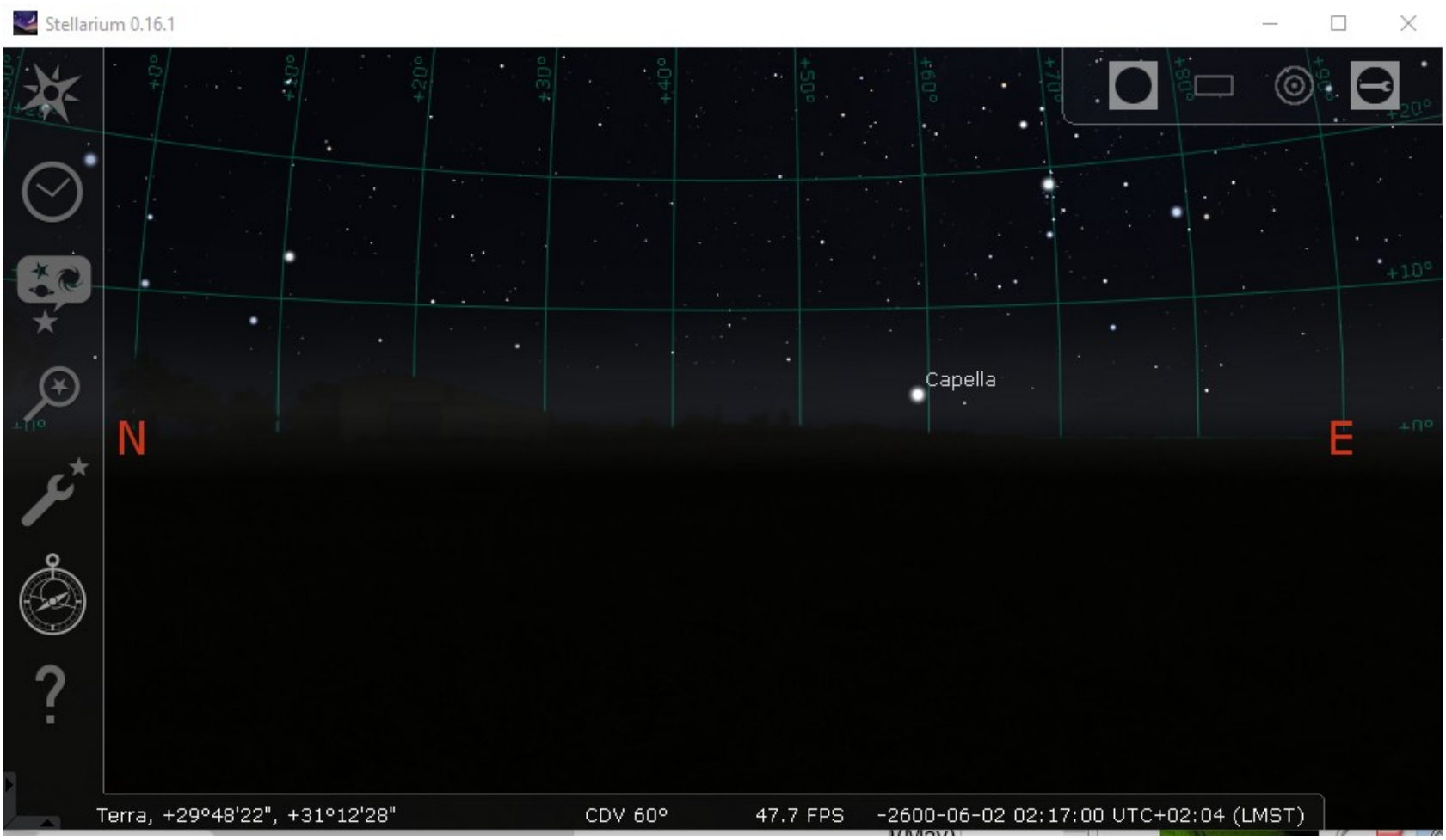

Figure 4: The direction of the rising of Capella was close to the direction of the causeway, according to a simulation by software Stellarium , 2600 BC.

In the web, we can find references to Capella and its role in the Egyptian sky.

"Capella was also apparently important in ancient Egypt. It appears on the Denderah Zodiac as a mummified cat" (http://humanityhealing.net/2011/06/capella-the-star-ofplenitude/). And also, "The nome of the Oryx that corresponded to Auriga and the goat Capella, was the site of the mythical battle between Horus and the god Seth as a gazelle" [8]. Therefore, an orientation to the rising of Capella is also possible. However, I consider more plausible an orientation to the northernmost direction of the moonrise.

\section{References}

[1] Maragioglio, V. \& Rinaldi, C. (1963). L'Architettura delle Piramidi Menfite, III. Artale.

[2] Hill, J. (2010). Dashur: Bent Pyramid of Sneferu. Ancient Egypt online. Available at http://www.ancientegyptonline.co.uk/bent-pyramid-dashur.html

[3] Sparavigna, A. C. (2017). The Zenith Passage of the Sun and the Architectures of the Tropical Zone. MECHANICS, MATERIALS SCIENCE \& ENGINEERING JOURNAL, 10(May), 1-12. Available at http://porto.polito.it/2695232/1/ID201704291_zenith.pdf 
[4] Lantero, Alessandro. Introduzione all' Archeoastronomia. Available at https://www.academia.edu/1607480/ INTRODUZIONE_ALL_ARCHEOASTRONOMIA [5] Sparavigna, A. C. (2016). The Karnak Temple and the Motion of the Earth's Axis (June 13, 2016). Available at SSRN: https://ssrn.com/abstract=2795239

[6] David Furlong. Egyptian Temple Orientation. Astronomical Alignment in the Temples of Egypt. Available at http://www.davidfurlong.co.uk/egyptarticle_temple_orient1.html [7] Sparavigna, A. C. (2017). Astronomical Orientations of the Great Enclosure of Musawwarat Es Sufra (February 15, 2017). Available at SSRN: https://ssrn.com/abstract=2918176 or http://dx.doi.org/10.2139/ssrn.2918176 [8] Berio, A. (2014). The Celestial River: Identifying the Ancient Egyptian Constellations. Sino-Platonic Papers, Number 253, p. 1-61, 253, 1-61. 